\title{
Editorial
}

\section{Amanece la participación ciudadana}

En 1999 comienzan a florear los aportes de la participación ciudadana que se sembraron, en 1997, con el documento Bases para un plan de nación. El terreno se venía preparando desde 1996, cuando aparecieron una serie de propuestas económicas de concertación nacional: El Manifiesto Salvadoreño de ANEP, el diagnóstico del FMNL, los programas de FUNDE y de FUSADES... Estas propuestas tenían un denominador común: la preocupación ante el rumbo impreso por el gobiemo actual y el deseo de que cada proyecto se prolongara en un diálogo abierto y concertado'.

En 1997, el presidente intenta realizar un cambio de agujas en la dirección y rumbo económicos. Una de las primeras determinaciones del gobierno había sido derruir el Ministerio de Planificación Económica. Tres años más tarde, en sus discursos del $1^{\circ}$ de mayo y $1^{\circ}$ de junio 1997 , declara públicamente que es necesario un Plan de nación que nos dé una visión a mediano y largo plazo que genere estabilidad, confianza y continuidad. Consciente o inconscientemente, esto constituyó una seria autocrítica a la improvisación de medidas económicas que han caraterizado a este gobiemo.

Este reto es aceptado por la comisión nombrada para redactar las bases de un plan de nación. Hay que confesar que los resultados superaron las expectativas iniciales ${ }^{2}$. El éxito de la comisión y de su valioso trabajo es que el documento Bases para un plan de nación se convirtió en un informe abierto al diálogo, a la consulta y a la participación, incluso de quienes viven en los más pobres y alejados departamentos. La apertura al diálogo encontró una franca respuesta porque se enunciaba la verdad: “En El Salvador, el nudo gordiano es la pobreza estructural que se asienta en una realidad más profunda, la marginación sociocultural derivada, a su vez, de la configuración y el funcionamiento tradicional del poder 
político" (p. 5 del documento). Fueron múltiples las exposiciones públicas del documento y todavía más las reuniones parroquiales. Las bases populares deseaban ser partícipes áctivos de esta novedad, de la apertura al diálogo.

Este deseo de participación ha recibido un nuevo impulso, muy valioso, por cuanto se trata de un aporte académico y profesional. Este ha sido el resultado de las 19 mesas de trabajo, producto de 211 especialistas salvadoreños que "de forma perseverante respondieron al llamado del país cuando se buscaban nuevos caminos hacia el siglo XXI". El documento "Temas claves para el Plan de nación: consulta especializada", de enero de 1999, aparece en el momento preciso y con el contenido preciso, llenando un vacío político.

Los meses previos a las elecciones presidenciales han sido decepcionantes; decepcionantes por la triste actuación y mediocres aportes de los partidos políticos. Aunque la excepción confirma la regla, las propuestas y los programas presentados, de momento, por la mayoría de los partidos contendientes han significado pérdida de tiempo y de dinero. Y con toda razón se les ha criticado porque no priorizaron, de manera ordenada, los objetivos y problemas que deben resolverse, ni avanzaron más allá de vagas generalidades. Fuera de las pintas con que ensuciaron la ciudad, poco fue lo que dijeron. Con toda razón, las encuestas de opinión pública acotan las más bajas calificaciones a la mayoría de partidos.

Esto es muy grave para el país, porque la creciente pérdida de confianza en esta estirpe política puede traducirse en un creciente absentismo electoral. Hemos llegado a la contradicción de contar con una ciudadanía deseosa de dar y participar frente a un abanico de partidos, muy partidos, que no ofrecen un asidero a la participación. La conclusión es desalentadora: la respuesta y la solución de los graves problemas del país encuentran vía cerrada en la casi totalidad de los partidos políticos. Por esta razón, la elaboración y la publicación de este plan de nación, realizada por estos 211 especialistas nacionales, viene a llenar no sólo un vacío político, sino que indica al próximo gobiemo de dónde le pueden llegar las soluciones más realistas, a quiénes debe consultar y, quizás, de quiénes debe rodearse.

Estando en la era de los pasos a nivel, el documento — presentado por las 19 mesas de trabajo- se convierte en el más amplio paso a nivel, de múltiples carriles, desde la ciudadanía académica hasta los directivos del gobiemo entrante. Este paso a nivel ha necesitado un tiempo de diseño y contrucción sobre un sólido armazón nacional y ad honorem. Detalle que muestra el deseo sincero de participación. Este aporte encierra dos grandes valores; en primer lugar sus contenidos especializados: la metodología del análisis, el detalle de los problemas y las propuestas de solución a corto, mediano y largo plazo. Es una agenda de trabajo para los tres poderes del Estado y sus correspondientes dependencias. Tanto o más importante que el mismo contenido del documento es el expreso deseo de una participación ciudadana, en este caso académicamente cualificada. 
La "mesa multidisciplinar de Washington", integrada por acreditados académicos cercanos a las instituciones financieras intermacionales, introduce su análisis con el acápite: "Plan de nación y poder ciudadano". El título primero se centra en el fortalecimiento de la democracia. Reconociendo los avances que se han hecho luego de los acuerdos de paz, señalan un conjunto de comportamientos que frenan los avances democráticos. "La impunidad, la corrupción, los enfrentamientos irresolubles, las negociaciones cupulares cerradas y otros vicios de la política van generando el distanciamiento de grandes sectores poblacionales del quehacer político, aun en democracias relativamente jóvenes. Este fenómeno, a veces más lentamente y otras con mayor celeridad, se termina traduciendo en el estrechamiento cada vez mayor del círculo que realmente ejerce el poder político. De ahí a una dictadura de corte oligárquico no hay más que un paso, que se suele dar aprovechando alguna coyuntura crítica".

De ahí fluye una conclusión lógica. "Es por lo anterior que, en la etapa en que se encuentra la democracia salvadoreña, se requieren mecanismos que incluyan en la reflexión sobre el país a sectores amplios, especialmente los que no tienen filiación política. Son también necesarios esquemas firmes que garanticen al ciudadano el ejercicio de pedirle cuentas a sus gobernantes y no solamente de elegirlos. Y, finalmente, se precisa un consenso básico y amplio sobre el destino del país, sancionado por el conjunto de la ciudadanía, que sirva de marco al juego de las fuerzas políticas y sociales". En resumen, este plan de nación se podría convertir en un instrumento que permitiera: "(1) Incorporar sectores amplios a la discusión sobre el país y su futuro. (2) Fortalecer la capacidad de exigir cuentas a los gobernantes. (3) Reafirmar un consenso nacional que enmarque posiciones políticas" (pp. 357-358).

Con la recepción y los aportes dados por las clases populares al documento Bases para un plan de nación, seguido de la valiosa investigación realizada por las 19 mesas de trabajo se ha completado la primera etapa ascendente de la participación ciudadana. Ahora fluye una interrogante: ¿qué respuesta institucional debe aportar el Estado a este plan de nación que nace de amplias bases cívicas? ¿Será este plan uno de los reguladores de la economía nacional? Sin duda este será un tema para la reflexión, o tal vez para debatir, en el presente año y quinquenio, porque la controversia aparece en algunas mesas de trabajo.

La mesa multidisciplinaria de Washington da una respuesta, algo abierta, al hablar de la adecuada función del Estado. "El desarrollo económico y social de El Salvador no es posible sino se cuenta con un Estado eficaz. Estado-socio y no Estado-dirigista. El Estado debe actuar como complemento de los mercados y no en sustitución de ellos" (p. 363). Esta afirmación ya plantea el debate sobre la integración de esos dos reguladores: el mercado y el Estado. Pero el problema mundial es que el llamado mercado, sobre todo el mercado financiero regulador del resto de mercados, ha entrado en grave crisis como agente de exclusión 
laboral y como generador de incontrolables desequilibrios nacionales. Antes y sobre todo después de 1997 difícilmente se puede decir que el mercado es el mejor regulador de la economía.

Hace dos décadas se decía que el Estado era el problema; ahora se vuelve a decir que el mercado es el problema. En la reunión de Davos - en Suiza, llevada a cabo del 28 de enero al de 2 de febrero- se han evaluado las consecuencias antisociales de la globalización, la reflexión o el debate es cómo, a partir de dos "problemas", resolvemos nuestros problemas nacionales. Esta discusión ya afloró desde los años veinte. Este grupo de acreditados economistas, ¿nos estarán dando alguna pista en el siguiente párrafo? "No se puede avanzar en la modernización del Estado sino se cuenta con instrumentos gubernamentales que definan las prioridades estratégicas, asignen recursos conforme a esas prioridades, den seguimiento a acciones y evalúen los resultados obtenidos ejerciendo el debido rendimiento de cuentas. Una unidad encargada de la planificación y evaluación que asuma la planificación, diseño, ejecución, evaluación y sustentabilidad de las inversiones públicas del Estado es una necesidad en los tiempos actuales y debe establecerse" (p. 364). Al hablar de la planificación del sector estatal, ¿se estará recomendando un Ministerio de Planificación nacional?

Era de esperarse que en la mesa de trabajo centrada en la modemización del Estado, apareciera el debate y tal vez una opinión concertada. Sin embargo, el redactor del grupo admitió que "no fue posible alcanzar un acuerdo en lo que deberían ser a un nivel más específico los roles del Estado moderno". La mesa deliberó sobre un párrafo del documento Bases para un plan de nación que literalmente dice: "La naturaleza del Estado como regulador subsidiario, garante o gestor está en juego en este debate que debe situarse en una dimensión constructiva, en función de la necesaria modernización del Estado. Es, indudablemente, un problema cuya decisión será fundamental para la viabilidad y el desarrollo del país a mediano y largo plazo".

El redactor de la mesa de trabajo comentó: "En la discusión sobre el rol del Estado se expresaron posiciones de carácter ideológico o doctrinario en torno a lo que debería ser el papel del Estado y el papel del mercado en un momento histórico específico. La relación Estado-Mercado es el tema de fondo que a veces se quiere soslayar" (p. 84). Uno de los autores citados sitúa acertadamente el problema: "Aprovechar la ventaja del mercado, limitando sus características concentradoras; aprovechar las ventajas de la intervención del Estado, sin caer en restricciones intolerables a la libertad social, es un objetivo difícil de lograr, pero cuya búsqueda es una obligación" (p. 85).

Ya es un avance hablar de la integración de los dos reguladores de la economía: Estado y mercado. Parece que la historia nos empuja, una vez más, hacia una economía mixta o economía concertada por una planificación indicativa; incluso hacia un Estado social de bienestar'. Un denominador común en las 
mesas de trabajo es el reconocimiento de un crecimiento sin equidad: sector rural, microempresa, discriminación de género, desintegración territorial, junto con la deficiente situación de la salud, educación, vivienda, infraestructura vial y de los servicios, son datos suficientes de la tradicional desigualdad. Si los diversos estratos de la ciudadanía han colaborado activa y eficazmente en la elaboración de un plan de nación, el nuevo gobiemo debe internalizarlo como el hilo conductor hacia el desarrollo humano sustentable. Esto exige como requisito mínimo la reconstrucción actualizada de un Ministerio de Planificación Económica y Desarrollo Social. Es totalmente necesario transcender los análisis de los agregados macroeconómicos que, a los ojos del Banco Central, bastaban para auscultar la salud de nuestra economía, para descender hasta los cimientos más concretos puestos al descubierto en las mesas de trabajo. Nos enfrentamos a dos modos o modelos de entender y de dirigir la economía. Esto sí requiere un nuevo estilo de Estado y de gobierno, que ojalá los partidos políticos traten de comprender.

Los aportes de las 19 mesas de trabajo debe ser un libro de cabecera en esta fase preelectoral para los electores y los elegidos. Como afirma la mesa multidisciplinar de Washington, nos queda una tarea por realizar: "Son tamblén necesarios esquemas firmes que garanticen al ciudadano el ejercicio de pedirle cuentas a sus gobernantes y no sólo de elegirlos. Y, finalmente, se precisa un consenso básico y amplio sobre el destino del país, sancionado por el conjunto de la ciudadanía que sirva de marco al juego de las fuerzas políticas y sociales".

\section{Notas}

1. ECA, 199, pp. 553-558.

2. Realidad, 1998, pp. 219-241.

3. ECA, 1996, pp. 865-887. 